\title{
Renal tubular acidosis and autoimmune liver disease
}

\author{
PETER L. GOLDING ${ }^{1}$ AND ALASTAIR S. M. MASON \\ From the Department of Gastroenterology, The London Hospital and Southampton General Hospital
}

SUMMARY Forty-two patients with autoimmune liver disease have been investigated. Renal tubular acidosis was detected in $60 \%$ of the patients with primary biliary cirrhosis, in $30 \%$ with active chronic hepatitis, and in one out of seven cases with cryptogenic cirrhosis. The presence of the defect of renal acidification was not related to the level of plasma potassium, copper, or total globulin, nor to the pattern of immunological abnormalities detected in the serum. It is suggested that autoimmune liver disease and renal tubular acidosis may be part of a systemic disorder in the pathogenesis of which immunological mechanisms are involved.

Renal tubular acidosis is a disorder of function in which the renal tubule is unable to acidify urine normally out of proportion to any reduction in the glomerular filtration rate. Adults with this defect frequently have hyperglobulinaemia and nonorgan specific autoantibodies present in the serum (Morris and Fudenberg, 1967; Mason and Golding, 1970) and it has been suggested that immunological mechanisms are involved in the development of the disorder in these patients (Talal, Zisman, and Schur, 1968).

Hyperglobulinaemia and non-organ specific autoantibodies are frequently present in the serum of patients with active chronic hepatitis, primary biliary cirrhosis, and cryptogenic cirrhosis (Doniach, Roitt, Walker, and Sherlock, 1966; Hobbs, 1970). It is probable that auto-allergic mechanisms are involved in the pathogenesis of these disorders, and the general term 'autoimmune liver disease' has been introduced to comprise these three hepatic syndromes (Doniach and Walker, 1969).

The concurrence of renal tubular acidosis and autoimmune liver disease has been recorded (Cohen and Way, 1962; Read, Sherlock, and Harrison, 1963; Seedat and Raine, 1965; Leeson and Fourman, 1967), but a systematic study of patients with autoimmune liver disease for the presence of a defect of renal acidification has not been reported previously. The present study was undertaken in order to determine the frequency with which renal tubular acidosis occurs in this syndrome.

\section{Patients and Methods}

Forty-two patients with autoimmune liver disease

Received for publication 3 November 1970.

${ }^{1}$ Please address requests for reprints to Dr P. L. Golding, Liver Unit, King's College Hospital, Denmark Hill, London SE5. under the care of physicians at The London Hospital, St Bartholomew's Hospital, and in the Wessex Region were investigated. The patients were divided into three groups on the basis of clinical, biochemical, and histological criteria.

Group I comprised 20 patients (19 females) with active chronic hepatitis; the ages ranged from 20 to 80 years. Group II comprised 15 patients (14 females) with primary biliary cirrhosis; the ages ranged from 46 to 49 years. Group III comprised seven patients with cryptogenic cirrhosis. They were all male and the ages ranged from 46-70 years.

At the time of investigation all patients were on a normal diet with unrestricted sodium intake and none were on diuretics.

It was considered unnecessary to perform an ammonium chloride test in those patients with an overt metabolic acidosis (plasma bicarbonate level below 20 m-equiv/l) while passing urine with a $p \mathrm{H}$ greater than 6.0 . In the other subjects, to detect the incomplete type of renal tubular acidosis, an ammonium chloride test was performed using the method of Wrong and Davies (1959). In normal subjects the urine $p \mathrm{H}$ should fall below $5 \cdot 2$, the maximum titratable acidity be above $24 \mu$-equiv/min, and the maximum ammonium excretion above $33 \mu$-equiv/min. Renal concentrating ability was tested by measuring the maximum urinary specific gravity obtained after the administration of 5 units of pitressin tannate in oil. A maximum specific gravity of less than 1.020 was considered abnormal. Urinary aminoacids were detected by two-dimensional paper chromotography. The plasma copper levels were measured on an atomic absorption spectrophotometer (Unicam SP 90) and the normal range in our laboratory is $70-150 \mu \mathrm{g} / 100 \mathrm{ml}$.

Autoantibodies were detected by an immuno- 
fluorescent technique using a 1 in 10 dilution of the patient's serum. A slide screening test for rheumatoid factor was performed using rheumatex (Colab

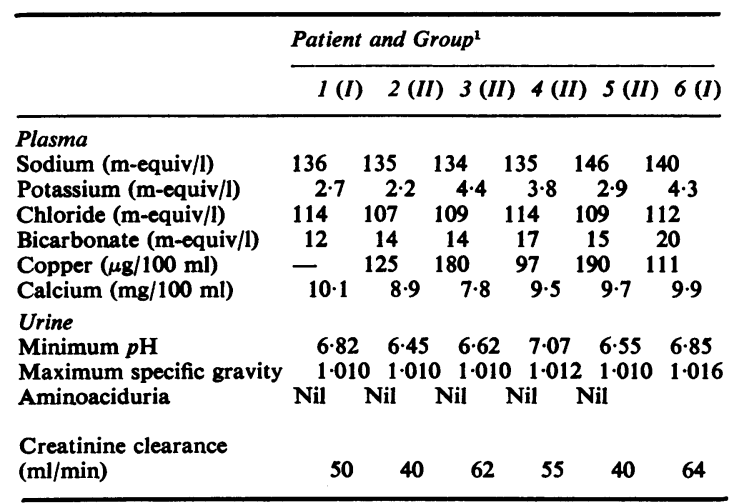

Table I Renal function in five patients with overt renal tubular acidosis

${ }^{1}$ Group I-patients with active chronic hepatitis, group II-primary biliary cirrhosis.
Laboratories, Chicago). The serum immunoglobulins were measured quantitatively by the single radial immunodiffusion method on an Immunoplate using the standards supplied by the manufacturer (Baxter, Thetford). The results have been expressed as a parcentage of the mean normal adult value (MNA), end are considered to be significantly elevated when greater than $175 \%$ MNA.

\section{Results}

\section{RENAL FUNCTION}

Sixteen patients $(38 \%)$ had renal tubular acidosis either of the overt or incomplete variety. Six cases were in group I, nine in group II, and one in group III.

An overt acidosis was present in six patients $(14 \%)$ and the results of the renal function tests are shown in Table I. All these patients had a hyperchloraemic acidosis, and three had hypokalaemia. The plasma copper concentration was elevated in three patients. All five patients had a urinary concentration defect and a reduced glomerular filtration rate, but none

\begin{tabular}{|c|c|c|c|c|c|c|c|c|c|c|}
\hline & \multicolumn{10}{|c|}{ Patient and Group } \\
\hline & $7(I)$ & $8(I)$ & $9(I)$ & $10(I)$ & $11(I I)$ & $12(I I)$ & $13(I I)$ & $14(I I)$ & $15(I I)$ & $16(I I I)^{1}$ \\
\hline $\begin{array}{l}\text { Plasma } \\
\text { Sodium (m-equiv/l) } \\
\text { Potassium (m-equiv/l) } \\
\text { Chloride (m-equiv/l) } \\
\text { Bicarbonate (m-equiv/l) } \\
\text { Copper }(\mu \mathrm{g} / 100 \mathrm{ml})\end{array}$ & $\begin{array}{c}137 \\
3.9 \\
98 \\
22 \\
180\end{array}$ & $\begin{array}{l}138 \\
4 \cdot 0 \\
93 \\
24 \\
-\end{array}$ & $\begin{array}{c}143 \\
3 \cdot 7 \\
106 \\
22 \\
93\end{array}$ & $\begin{array}{l}136 \\
3 \cdot 1 \\
99 \\
30 \\
-\end{array}$ & $\begin{array}{c}135 \\
4 \cdot 2 \\
97 \\
23 \\
137\end{array}$ & $\begin{array}{l}140 \\
3 \cdot 5 \\
101 \\
25 \\
56\end{array}$ & $\begin{array}{c}142 \\
3 \cdot 4 \\
104 \\
22 \\
140\end{array}$ & $\begin{array}{c}137 \\
3 \cdot 9 \\
101 \\
23 \\
175\end{array}$ & $\begin{array}{l}138 \\
3 \cdot 9 \\
103 \\
25 \\
186\end{array}$ & $\begin{array}{l}140 \\
4 \cdot 0 \\
96 \\
24 \\
-\end{array}$ \\
\hline $\begin{array}{l}\text { Urine }^{2} \\
\text { Minimum } p H \\
\text { Maximum titrate acidity ( } \mu \text {-equiv/min) } \\
\text { Maximum NH4 ( } \mu \text { equiv/min) } \\
\text { Maximum specific gravity }\end{array}$ & $\begin{array}{l}5 \cdot 61 \\
14 \\
96 \\
1.024\end{array}$ & $\begin{array}{l}6.07 \\
24 \\
96 \\
1.022\end{array}$ & $\begin{array}{l}6 \cdot 25 \\
19 \\
74 \\
-\end{array}$ & $\begin{array}{l}6 \cdot 15 \\
20 \\
42 \\
1 \cdot 010\end{array}$ & $\begin{array}{l}5 \cdot 83 \\
19 \\
131 \\
1 \cdot 020\end{array}$ & $\begin{array}{l}5 \cdot 71 \\
18 \\
55 \\
1.010\end{array}$ & $\begin{array}{l}6 \cdot 17 \\
21 \\
63 \\
1 \cdot 010\end{array}$ & $\begin{array}{l}5.42 \\
18 \\
52 \\
1.022\end{array}$ & $\begin{array}{c}6.92 \\
4 \\
68 \\
-\end{array}$ & $\begin{array}{l}5 \cdot 53 \\
23 \\
162 \\
1 \cdot 010\end{array}$ \\
\hline
\end{tabular}

Table II Renal function in 10 patients with incomplete renal tubular acidosis

${ }^{1}$ Group III-cryptogenic cirrhosis.

2Values measured during an acid load test.

\begin{tabular}{|c|c|c|c|c|c|c|c|c|c|}
\hline \multicolumn{2}{|l|}{ No. of Patients } & \multicolumn{4}{|c|}{ Autoantibodies } & \multicolumn{4}{|l|}{ Immunoglobulins } \\
\hline $\begin{array}{l}\text { With Renal Tubular } \\
\text { Acidosis }\end{array}$ & $\begin{array}{l}\text { Without } \\
\text { Renal Tubular } \\
\text { Acidosis }\end{array}$ & $\begin{array}{l}\text { Rheumatoid } \\
\text { Factor }\end{array}$ & $\begin{array}{l}\text { Antinuclear } \\
\text { Antibody }\end{array}$ & $\begin{array}{l}\text { Smooth } \\
\text { Muscle } \\
\text { Antibody }\end{array}$ & $\begin{array}{l}\text { Mito- } \\
\text { chondrial } \\
\text { Antibody }\end{array}$ & $\begin{array}{l}\operatorname{IgG} \\
(>175 \% M N A)^{1}\end{array}$ & $\begin{array}{l}\operatorname{lgA} \\
(>175 \% M N A)\end{array}$ & $\begin{array}{l}\operatorname{IgM} \\
(>175 \% M N A)\end{array}$ & $\begin{array}{c}\text { Monower } \\
\text { IgM } \\
\\
\sigma \\
\sigma\end{array}$ \\
\hline $\begin{array}{l}\text { Active chronic hepatitis } \\
6\end{array}$ & 14 & $\begin{array}{l}3 \\
8\end{array}$ & $\begin{array}{l}4 \\
7\end{array}$ & $\begin{array}{l}3 \\
6\end{array}$ & $\begin{array}{l}2 \\
2\end{array}$ & $\begin{array}{l}1 \\
9\end{array}$ & $\begin{array}{l}2 \\
4\end{array}$ & $\begin{array}{l}2 \\
9\end{array}$ & $\begin{array}{ll}2 & \stackrel{0}{c} \\
0 & \mathbb{D}\end{array}$ \\
\hline $\begin{array}{l}\text { Primary biliary cirrhosis } \\
9\end{array}$ & 6 & $\begin{array}{l}5 \\
4\end{array}$ & $\begin{array}{l}2 \\
0\end{array}$ & $\begin{array}{l}2 \\
1\end{array}$ & $\begin{array}{l}9 \\
6\end{array}$ & $\begin{array}{l}7 \\
4\end{array}$ & $\begin{array}{l}3 \\
1\end{array}$ & $\begin{array}{l}7 \\
6\end{array}$ & $\begin{array}{ll}0 \\
\mathbf{0} & \stackrel{7}{+} \\
\mathbf{0} & \end{array}$ \\
\hline Cryptogenic cirrhosis & 6 & $\begin{array}{l}\mathbf{0} \\
\mathbf{3}\end{array}$ & $\begin{array}{l}1 \\
3\end{array}$ & $\begin{array}{l}\mathbf{0} \\
\mathbf{2}\end{array}$ & $\begin{array}{l}0 \\
1\end{array}$ & $\begin{array}{l}\mathbf{0} \\
\mathbf{2}\end{array}$ & $\begin{array}{l}0 \\
5\end{array}$ & $\begin{array}{l}\mathbf{0} \\
\mathbf{2}\end{array}$ & $\begin{array}{ll}\mathbf{0} & \stackrel{\overrightarrow{\mathbb{D}}}{\stackrel{\mathbb{D}}{\mathbb{D}}} \\
\mathbf{0} & \stackrel{0}{\stackrel{0}{*}}\end{array}$ \\
\hline $\begin{array}{l}\text { Total } \\
16\end{array}$ & 26 & $\begin{array}{l}50 \% \\
58 \%\end{array}$ & $\begin{array}{l}44 \% \\
38 \%\end{array}$ & $\begin{array}{l}31 \% \\
35 \%\end{array}$ & $\begin{array}{l}72 \% \\
35 \%\end{array}$ & $\begin{array}{l}50 \% \\
58 \%\end{array}$ & $35 \%$ & $\begin{array}{l}56 \% \\
66 \%\end{array}$ & $12 \%$ ত \\
\hline
\end{tabular}



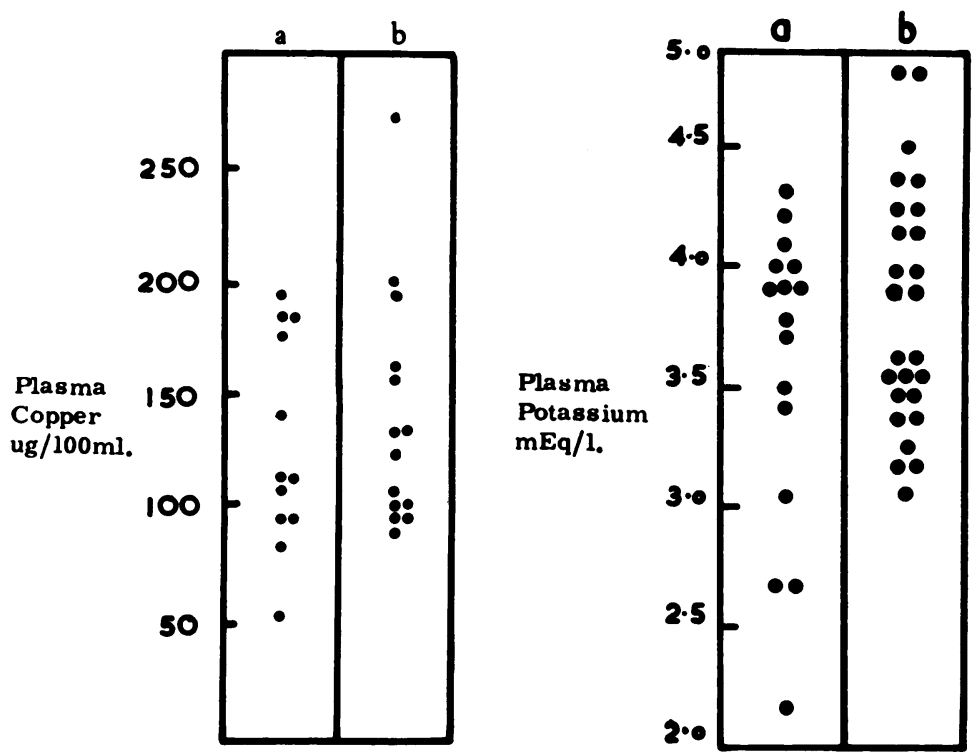

Fig. 1. Comparison of plasma potassium and copper levels in patients (a) with and (b) without renal tubular acidosis.

of them had aminoaciduria or glycosuria. One patient (case 3) had hypocalcaemia with histological and radiological evidence of osteomalacia.

An abnormal response to an acid load was found in 10 patients $(24 \%)$. The results of the renal function investigations in these cases are shown in Table II. Hypokalaemia was detected in two patients, and three had a raised level of plasma copper.

A normal response to an acid load was found in the remaining 26 patients. The levels of plasma potassium, copper, and total globulin in these patients are compared with those detected in the patients with renal tubular acidosis in Figures 1 and 2. There was no significant difference in the concentration of either plasma potassium, copper, or total globulin between those patients with and those without renal tubular acidosis. The three lowest plasma potassium levels, however, were in patients with overt renal tubular acidosis.

\section{IMMUNOLOGICAL INVESTIGATIONS}

The prevalence of autoantibody and immunoglobulin abnormalities is shown in Table III, where each group has been divided into those patients with and those without renal tubular acidosis. The autoantibodies detected and the elevation of serum immunoglobulins in each group correspond to those commonly found in each liver disorder (Doniach et al, 1966; Hobbs, 1970). The presence of renal tubular acidosis is not related either to the levels or class of immunoglobulin elevated. Mitochondrial antibody was detected in $72 \%$ of the patients with

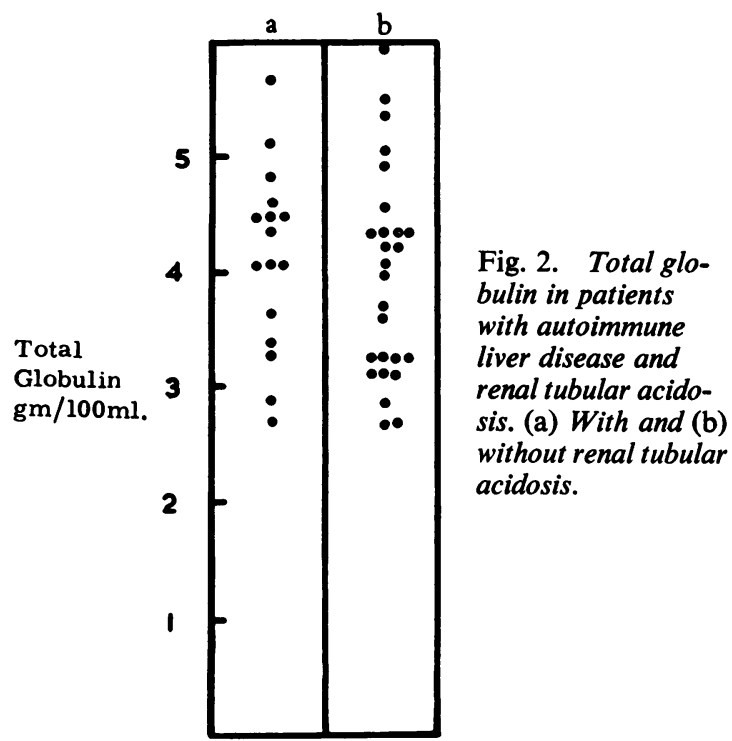

renal tubular acidosis, but in only $35 \%$ of the patients without defect of acidification. The other autoantibodies were found with equal frequency in those patients with and those without renal tubular acidosis.

\section{Discussion}

A defect of urinary acidification was found in $38 \%$ of the patients in this series. A systematic investigation of patients with autoimmune liver disease for 
the presence of such a defect of acidification has not previously been recorded, although sporadic reports have suggested that the two disorders are associated. Read et al (1963) noted that three of the patients in their series of 81 cases of active chronic hepatitis had renal tubular acidosis. Single cases with both renal tubular acidosis and active chronic hepatitis have been described by Cohen and Way (1962) and Seedat and Raine (1965). Smith, Middleton, and Williams (1967) reported a patient with renal tubular acidosis associated with cirrhosis whom we have reinvestigated and included in this series. Active chronic hepatitis was detected in one of the seven patients with renal tubular acidosis reported by Talal et al (1968), and in one of the four cases of renal tubular acidosis in the series recorded by Morris and Fudenberg (1967). The concurrence of renal tubular acidosis and primary biliary cirrhosis has been noted only once previously (Leeson and Fourman, 1967).

Shear, Bonkowsky, and Gabuzda (1969) investigated 15 patients with hepatic cirrhosis of undetermined aetiology, and found an abnormal response to an acid load in nine cases $(60 \%)$, two of which had an overt acidosis. The frequent finding of renal tubular acidosis in their series may be explained by the selection of cases for study as those patients with persistent hypokalaemia were particularly investigated and renal tubular acidosis is a known cause of hypokalaemia (Fourman and McCance, 1955).

In potassium deficiency the ability of the kidney to secrete a maximally acid urine is impaired but ammonium excretion remains normal (Clarke, Evans, Macintyre, and Milne, 1955). Hypokalaemia was detected in only five of the 16 patients with renal tubular acidosis in our series and in two of these the deficiency was corrected before administering the acid load. Thus it is unlikely that a low plasma potassium concentration is responsible for the development of the renal lesion. However, the tubular defect may be a contributing factor to the low potassium levels found in patients with chronic liver disease.

A disturbance of the peritubular circulation due to hyperglobulinaemia has been suggested as a cause of renal tubular acidosis but we could find no correlation between the level of serum globulin and the presence of the disorder (Fig. 2), thus confirming the findings of Morris and Fudenberg (1967), Shearn and Tu (1968), and Tu, Shearn, Lee, and Hopper (1968).

Leeson and Fourman (1967) suggested that the defect of acidification in their patient with primary biliary cirrhosis was due to the deposition of copper in the renal tubules as a consequence of raised levels of plasma copper. The plasma copper concentration was measured in 12 of our patients with renal tubular acidosis and only five had an elevated value. No significant difference in the plasma copper levels was found between those patients with and those without renal tubular acidosis. It is unlikely that an abnormality of copper metabolism is a major factor in the development of the renal lesion in our patients.

In 10 cases of osteomalacia of intestinal or dietary origin reported by Muldowney, Freaney, and McGeeney (1968) renal tubular acidosis was found in five, two of whom also had abnormal aminoaciduria. The concurrence of coeliac disease with renal tubular acidosis was later reported (MacCuish, Munro, and Lamb, 1970). Both groups of authors suggested that the renal lesion may be due to a deficiency of vitamin $\mathrm{D}$ causing secondary hyperparathyroidism, rather than a deficiency of vitamin D per se. Investigations to detect malabsorption were performed in all our patients with primary biliary cirrhosis and only one (case 3 ) had radiological evidence of osteomalacia. Plasma calcium levels and bone radiographs were normal in the other eight patients with primary biliary cirrhosis and renal tubular acidosis, and it is thus unlikely that secondary hyperparathyroidism was responsible for the renal lesion in these patients.

Autoimmune liver disease and renal tubular acidosis are frequently associated with hyperglobulinaemia and the presence of non-organ specific autoantibodies and it has been suggested that auto-allergic mechanisms are involved in the pathogenesis of both disorders (Doniach et al, 1966; Hobbs, 1970; Mason and Golding, 1970). Abnormalities of the serum immunoglobulins were detected in all the patients with both renal tubular acidosis and autoimmune liver disease, but the presence of the acidification defect was not related either to the level or class of immunoglobulin elevated.

With the exception of mitochondrial antibody, autoantibodies were found with equal frequency in those patients with and those without renal tubular acidosis. The increased frequency of mitochondrial antibody $(72 \%)$ in the group with renal tubular acidosis is probably explained by the fact that this group contained a large number of cases of primary biliary cirrhosis $(56 \%)$, a condition known to be associated with a high incidence of mitochondrial antibody (Doniach et al, 1966). In the group without renal tubular acidosis only $23 \%$ of the cases had primary biliary cirrhosis. It is unlikely that mitochondrial antibody is an immunological marker indicating the presence of a defect of acidification, as in a larger series of 21 patients with a variety of autoimmune abnormalities in association with renal tubular acidosis whom we have investigated only 11 $(52 \%)$ showed mitochondrial immunofluorescence 
of the serum (Mason and Golding, unpublished observation).

The precise mechanisms producing the renal and hepatic abnormalities are not known but it is possible that immunological processes could be involved in the pathogenesis of both disorders. Lymphocytic infiltration of the renal cortex with tubular degeneration has been demonstrated in patients with renal tubular acidosis in association with other diseases of autoimmunity (Kaltreider and Talal, 1969; Shioji, Furuyama, Onodera, Saito, Ito, and Sasaki, 1970). Similar lymphocytic and plasma cell infiltration of the liver is the usual finding in the patients with autoimmune liver disease. It is interesting to note that dense lymphocytic infiltration of the kidney was found at necropsy in a case of primary biliary cirrhosis reported by MacKay (1960) but no renal function studies were reported.

Thus although defects of urinary acidification may arise from several different mechanisms it is possible that renal tubular acidosis and autoimmune liver disease may form part of a systemic disorder capable of affecting many organs (Mason and Golding, 1970; Mason, Mclllmurray, Golding, and Hughes, 1970). Further clinical, experimental, and histological studies are required to elucidate the immunological abnormalities and pathological processes responsible for the development of both disorders.

We would like to thank Dr J. Bamforth, Dr A. Dawson, and the physicians of the London Hospital for permission to study their cases, and also Dr G. Franglen of St George's Hospital and Mr R. Lloyd of Bournemouth Autoimmune Laboratories for their considerable help with the immunological investigations.

\section{References}

Clarke, E., Evans, B. M., Macintyre, I., and Milne, M. D. (1955). Acidosis in experimental electrolyte depletion. Clin. Sci., 14, 421-440.
Cohen, A., and Way, B. J. (1962). The association of renal tubular acidosis with hyperglobulinaemic purpura. Aust. Ann. Med., 11, 189-194.

Doniach, D., Roitt, I. M., Walker, J. G., and Sherlock, S. (1966). Tissue antibodies in primary biliary cirrhosis, active chronic lupoid hepatitis, cryptogenic cirrhosis and other liver disease and their clinical implications. Clin. exp. Immunol., 1, 237-262.

Doniach, D., and Walker, J. G. (1969). A unified concept of autoimmune hepatitis. Lancet, 1, 813-815.

Fourman, P., and McCance, R. A. (1955). Tetany complicating the treatment of potassium deficiency in renal acidosis. Lancet, 1 , 329-331.

Hobbs, J. R. (1970). Immune globulins in some diseases. Brit. J. Hosp. Med., 3, 669-680.

Kaltrieder, H. B., and Talal, N. (1969). Impaired renal acidification in Sjögren's syndrome and related disorders. Arthr. and Rheum., 12, 538-541.

Leeson, P. M., and Fourman, P. (1967). A disorder of copper metabolism treated with penicillamine in a patient with primary biliary cirrhosis and renal tubular acidosis. Amer. J. Med., 43, 620-635.

MacCuish, A. C., Munro, J. F., and Lamb, W. L. (1970). Reversible renal tubular defects in gluten enteropathy with osteomalacia. Brit. med. J., 2, 343-344.

MacKay, I. R. (1960). Primary biliary cirrhosis. Lancet, 2, 521-523.

Mason, A. S., and Golding, P. L. (1970). Hyperglobulinaemic renal tubular acidosis. Brit. med. J. 3, 143-146.

Mason, A.M. S., McIllmurray, M., Golding, P. L., and Hughes, D.J.T. (1970). Fibrosing alveolitis associated with renal tubular acidosis: a report of 9 cases. Brit. med. J. In press.

Morris, R. C., and Fudenberg, H. H. (1967). Impaired renal acidification in patients with hypergammaglobulinemia. Medicine (Baltimore), 46, 57-69.

Muldowney, F. P., Freaney, R., and McGeeney, D. (1968). Renal tubular acidosis and amino-aciduria in osteomalacia of dietary or intestinal origin. Quart. J. Med., 37, 517-539.

Read, A. E., Sherlock, S., and Harrison, C. V. (1963). Active juvenile cirrhosis considered as part of a systemic disease and the effect of corticosteroid therapy. Gut, 4, 378-393.

Seedat, Y. K., and Raine, E. R. (1965). Active chronic hepatitis associated with renal tubular acidosis and successful pregnancy. S. Afr. Med. J., 39, 595-597.

Shear, L., Bonkowsky, H. L., and Gabuzda, G. J. (1969). Renal tubular acidosis in cirrhosis. New Engl. J. Med., 280, 1-7.

Shearn, M. A., and Tu, W. H. (1968). Latent renal tubular acidosis in Sjøgren's syndrome. Ann. Rheum. Dis., 27, 27-32.

Shioji, R., Furuyama, T., Onodera, S., Saito, H., Ito, H., and Sasaki, Y. (1970). Sjögren's syndrome and renal tubular acidosis. Amer. J. Med., 48, 456-463.

Smith, P., Middleton, J. E., and Williams, R. (1967). Renal tubular acidosis and cirrhosis. Postgrad. med. J., 43, 439-442.

Talal, N., Zisman, E., and Schur, P. H. (1968). Renal tubular acidosis, glomerulonephritis and immunologic factors in Sjögren's syndrome. Arth. and Rheum., 11, 774-786.

Tu, W. H., Shearn, M. A., Lee, J. C., and Hopper, J. (1968). Interstitial nephritis in Sjögren's syndrome. Ann. intern. Med., 69, 1163-1170.

Wrong, O. M., and Davies, H. E. F. (1959). The excretion of acid in renal disease. Quart. J. Med., 28, 259-313. 